\title{
Reflective practices for quality education in Malaysia: A mixed method approach
}

\author{
S. Chee Choy ${ }^{1 *}$, Joanne Sau-Ching Yim ${ }^{2}$, and Daljeet Singh $\mathrm{Sedhu}^{3}$, and Azlinda Boheran Nudin ${ }^{4}$ \\ ${ }_{1,2,4}$ Tunku Abdul Rahman University College, Perak Branch Campus, Malaysia. \\ ${ }^{3}$ Universiti Teknologi Mara, Cawangan Perak, Kampus Seri Iskandar, Malaysia
}

\begin{abstract}
Teachers in Malaysia are expected to possess the necessary reflective skills to help them analyse and think through classroom situations that require diplomacy and sound judgement. This study examined the contributions of lifelong learning skills, self-assessment ability, self-belief, teaching awareness and reflective thinking in explaining the differences in teaching practices among Malaysian pre service teachers (PSTs). A mixed-methods approach was used to provide pragmatic knowledge that can be applied to further develop reflective thinking practices among PSTs. The sample of this study were 387 PSTs enrolled in Bachelor level programmes from which 11 of them volunteered to participate in the interviews. The quantitative data showed lifelong learning skills, self-belief, and teaching awareness had a significant relationship with reflective thinking. From the qualitative data analysis, PSTs were generally focused on the immediate challenge of becoming better teachers and were open to further education in time. Similarly, the results of the qualitative thread showed the PSTs were able to manage their planning, monitoring of students and evaluation of themselves and their relation to students, suggesting metacognitive awareness, a good indicator of established reflective thinking processes. Future studies will need to consider how this will influence how reflective thinking is carried out when they are practicing teachers.
\end{abstract}

\section{Introduction}

Malaysia has a highly centralised education system compared to other countries in the OECD (Hanushek \& Woessmann, 2015). All Malaysian schools are under the purview of the Ministry of Education which is governed by the Education Act 1996 and teachers must possess relevant professional qualifications and licences to work. In Malaysia, PSTs are observed to lack certain important qualities that have been identified as crucial for becoming effective teachers ranging from fundamental pedagogical knowledge to reflective thinking practices (Kabilan, 2007). Further to this a lack of understanding on how these qualities can be nurtured have resulted in uncritical and uninspiring pedagogical discussions even among practicing teachers (Tan \& Halili, 2015) and this has led to a decline in quality teaching and ultimately quality learning. Nambiar and Thang (2015) found differences among science, mathematics and English teachers in terms of their willingness to practise reflective thinking in an on-line community blog. English teachers were most willing to share critical and reflective thoughts about their practices while mathematics teachers showed the least willingness.

Many teachers especially the novice ones perceive they had no time for reflection and a lack of feedback on the quality of their work have not encouraged the practice (Senom, Zakaria \& Shah, 2013). Despite having adopted a competency based approach, which incorporates reflective thinking in order, to achieve high teaching quality in Malaysia, it cannot be ignored that the persistent observation of low quality teaching may be the functions of inadequate support and lack of resources in schools for improvement (Goh \& Wong, 2014). Malaysian teachers are expected to incorporate critical thinking into their lessons and the reason they are not able to effectively incorporate this form of thinking maybe caused by their inability to think reflectively (Choy \& Oo, 2012).

\subsection{Educational sector: embedding of reflective thinking as quality teaching}

Reflective thinking practices is part of the curriculum of teacher education (Mustapha, 2013). Built into the structure of the teacher education programme is the practicum which allow pre-service teachers the opportunity to put theory into practice in the classroom. During the practicum, emphasis is placed on all aspects of teaching professionally, which includes reflective practices as outlined in the 'Standard Guru Malaysia' [Malaysian Teachers' Standard] which was implemented in 2009 (Mustapha, 2013). All pre-service teachers (PST) need to possess reflective skills, as it is one of the abilities to demonstrate competencies in two areas: having professional knowledge and competence in executing teaching and learning activities in classrooms (Ong, Swanto, \& Al-Saqqaf, 2018). Reflective thinking is enforced through a designated reflection form that is filled by all PST during their practicum, which reflect the issues faced, analysis of strength and weakness of the particular issues, and suggestion for improvement (Ministry of Education, 2015).

Embedded into the Malaysia Education blueprint (2013-2025) is also a call for the transformation of the education sector to have teachers who can think reflectively and critically in order to develop the desired skills in their students (Nasir \& 
Sulaiman, 2015). Senom et al (2013) found that although reflective thinking was a required practice among teachers, many of them perceived they had no time to carry it out effectively. They were constrained by their inadequate and irrelevant teacher preparation course, fatigue, time consuming and tedious teaching preparation and lesson planning as well as difficulty when applying theory to practice. Nordin, Alias and Siraj (2013) noted that all Institutions of Higher Education (IHLs) in Malaysia have to revise standards and specifications which lack flexibility in their programmes so as to accommodate reflection and freedom to propose ideas in order to increase creativity and quality. This freedom for reflection and creativity was not emphasised previously resulting in rote learning and disengaged students (Kek \& Huijser, 2011).

\subsection{Defining reflective thinking practice}

In defining reflective thinking practice, the proposition Rodgers (2002) is considered. First, there is no differentiation of reflective thinking and systematic thinking. Secondly, the process of assessment of this skill is unclear. Thirdly, as this form of thinking cannot be clearly observed, it can be hard to determine its influence on student learning and their self-development. Reflective thinking will only begin when there is a problem or situation that needs to be reconsidered (Lee, 2005). Reflective thinking can give rise to the formation of the connection between a course of study and students' experience, producing a distinctly individualised that can energise learning (Cox, 2005). It has also been described as the coordination of professional engagements and critical evaluation of behaviours (Choy, Yim \& Tan, 2017). Reflective thinking is described in this study as a capability to reflect on one's educational activities while engaging in a continuous learning process.

\section{Mixed-Methods Research Designs}

Based on the afore-mentioned literature, the present study employed a mixed-methods strategy (Figure 1) to acquire a balanced analysis of the data, as well as to obtain a cross verification of findings from data acquired through quantitative and qualitative methods. Such an approach can offer pragmatic knowledge which draw closer the quantitative and qualitative divide to advance reflective thinking practices in PSTs. Creswell and Plano Clark (2011) defined mixed-methods design as the process of mixing two forms of data concurrently by combining them sequentially, having one build on the other. Hence, this method of research will allow researchers to produce knowledge and information that is useful to what is needed in practice. The approach employed acknowledges that knowledge produced is relative and not absolute, especially when there may be underlying associations which are transitory yet difficult to identify (Feilzer, 2010).

\subsection{Purpose}

The current study investigated the contributions of lifelong learning skills, self-assessment ability, self-belief, teaching awareness and reflective thinking in accounting for reflective thinking practices among pre-service teachers. As we were interested in attaining a more complete understanding of reflective thinking practices, the convergent parallel design (Creswell \& Plano Clark, 2011) was applied to the study. In this design, the qualitative and quantitative sources were considered concurrently during the research process. Both strands of the research were kept independent during analysis and subsequently the two sets of results were mixed to give a more complete picture of reflective thinking practices among PSTs.

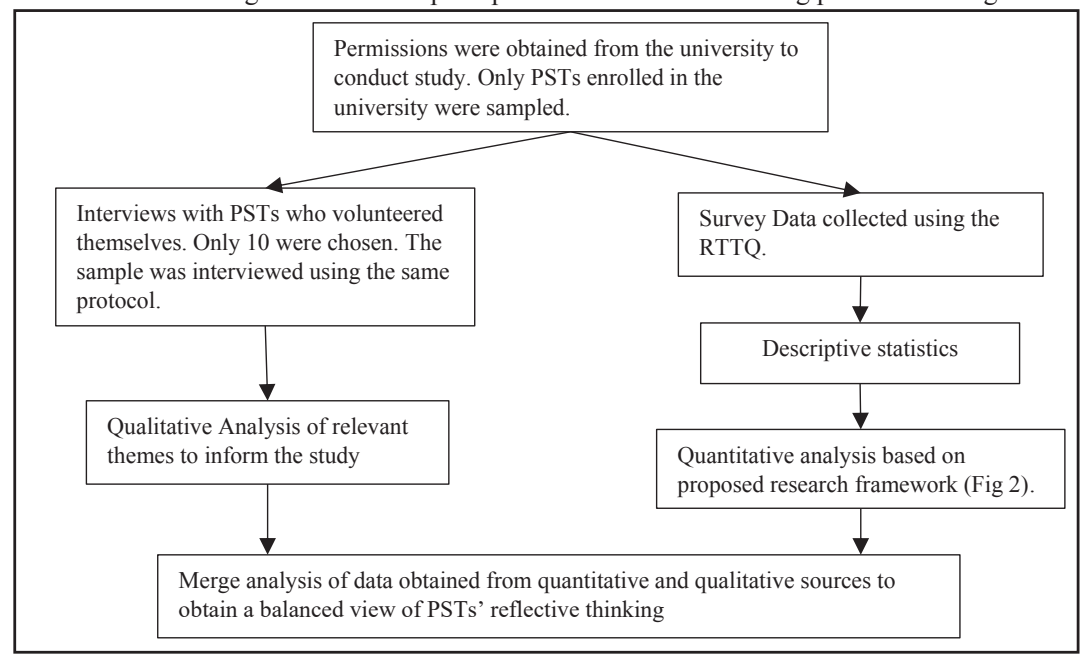

Figure 1. Mixed methods convergent parallel design and analytic procedures 


\section{Method}

\subsection{The quantitative phase}

The quantitative phase of the study used scale items from the Reflective Thinking for Teachers Questionnaire (RTTQ) (Choy, Yim \& Tan, 2017) to measure the five constructs in the conceptual framework (Figure 2).

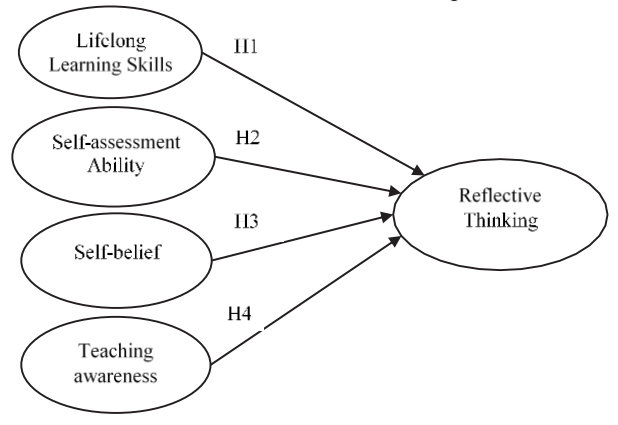

Figure 2. Research framework

Table 1. Definitions

\begin{tabular}{|l|l|l|}
\hline Construct & \multicolumn{1}{|c|}{ Definition } & Literature \\
\hline $\begin{array}{l}\text { Reflective } \\
\text { thinking }\end{array}$ & $\begin{array}{l}\text { The process of reflecting on actions in order to continuously learn } \\
\text { and self-develop, which require the consideration of the larger } \\
\text { context, meaning, and implications of an action. }\end{array}$ & $\begin{array}{l}\text { Choy et al. (2017); Cox } \\
\text { (2005) }\end{array}$ \\
\hline $\begin{array}{l}\text { Lifelong } \\
\text { learning } \\
\text { skills }\end{array}$ & $\begin{array}{l}\text { The self-motivated search of knowledge for continuous } \\
\text { professional and/or personal reasons which give rise to learning } \\
\text { from errors ending in the formation of reflective thinking } \\
\text { abilities. }\end{array}$ & $\begin{array}{l}\text { Buehl and Fives (2009); } \\
\text { Quendler and Lamb (2016) }\end{array}$ \\
\hline $\begin{array}{l}\text { Self- } \\
\text { assessment } \\
\text { ability }\end{array}$ & $\begin{array}{l}\text { The process of examining experiences that encourage self- } \\
\text { reflection through identification of standards and making } \\
\text { judgements of the experience. }\end{array}$ & Clara (2014), Rodgers (2002) \\
\hline Self-belief & $\begin{array}{l}\text { Perception of one's teaching and relationship with students which } \\
\text { can motivate and drive to improve the skill. }\end{array}$ & $\begin{array}{l}\text { Crosswell and Beutel (2017); } \\
\text { Williams and Burden (1997) }\end{array}$ \\
\hline $\begin{array}{l}\text { Teaching } \\
\text { awareness }\end{array}$ & $\begin{array}{l}\text { The ability to influence students which can stimulate self- } \\
\text { assessment and self-evaluation }\end{array}$ & Farrell (2015); Lee (2005) \\
\hline
\end{tabular}

\subsubsection{Rationale for the hypothesis}

The relation of experiences and lifelong learning skills, the voluntary pursuit of knowledge that is self-motivated can represent the lifelong learning process (Quendler \& Lamb, 2016). Buehl and Fives (2009) found that lifelong learning can bring about the reflection of an individual's learning experience. Hence the hypothesis:

(H1): Reflective thinking will be significantly influenced by lifelong-learning.

In the course of evaluating individual experiences leading to self-assessment, this can result in new perceptions and future approaches (Clara 2014). There is undeniably a close association between self-assessment and reflection, as some degree of thoughts based on teaching knowledge and self-awareness is required for self-assessment (Rodgers, 2002). Therefore, the following hypothesis is proposed:

(H2): Reflective thinking will be significantly influenced by self-assessment ability.

Self-belief is conceptualised as the perception of teachers' own capabilities and students' relationships will affect the way they in the classroom, as well as predict teachers' resilience (Crosswell \& Beutel, 2017; Williams \& Burden, 1997). Teachers who engage in reflection of their teaching will be able to boost in self-belief through the process as awareness of the self is enforced with each reflection (Travers, Morisano, \& Locke, 2015). Hence, we propose the following hypothesis: 
(H3): Reflective thinking will be significantly influenced by self-belief.

Teaching awareness is conceptualised as teachers' awareness of their influence on students. In education, reflective thinking should not be a pathway to solve problems but also an extent of awareness about particular learning situations (Lee, 2005). This is echoed in a meta-analysis study that supported the advantages of reflective thinking practices in advancing opportunities by producing solutions for teachers and motivated further exploration (Farrell, 2015). With this, the following hypothesis is proposed:

(H4): Reflective thinking will be significantly influenced by teaching awareness.

\subsubsection{Participants and data collection}

Permission to conduct research from the university concerned was obtained. Respondents consisted of PSTs who enrolled in Bachelor degree programme in a Malaysian education university. Participants were approached and informed about their rights to withdraw from the study at any juncture of time. The identities of respondents were also kept in confidence. Data collected were assessed for outliers and respondents' engagement were screened whereby we deleted straight-lined responses. There was a total of 387 responses, satisfying $90 \%$ of the statistical power at an $\alpha$ level of 0.05 (G*Power). Among the respondents, there were $302(78.0 \%)$ females and $85(22.0 \%)$ males with a mean age of 22.22 years old $(\mathrm{SD}=1.458)$. The PSTs are enrolled in Year $1(32.2 \%)$, Year $2(33.1 \%)$, Year $3(7.8 \%)$, and Year 4 (26.9\%) respectively. In terms of practicum experience, $59.4 \%$ had their training while $40.6 \%$ have yet to receive practicum training.

\subsubsection{Measures}

The questionnaire items were adopted from Reflective Thinking for Teachers Questionnaire (Choy et al, 2017). The questionnaire contains 28 items, some examples of these items are: "The way lessons carried out are important indicators of effectiveness" (life-long learning), "Students' feedback are important" (self-assessment), "Realisation that mistakes made can have influence on students" (self-belief), "Awareness of practices that will influence teaching behaviour" (teaching awareness), and "Spending much time in reflecting on practices" (reflective thinking).

\subsubsection{Measurement model evaluation}

Internal consistency of the variables was assessed with composite reliability (CR). In terms of validity average variance extracted (AVE) was examined for convergent validity, while Fornell-Larcker criterion was used to establish discriminant validity. The items in the questionnaire were also examined for its relevance in the assigned variables, four items with loadings less than .70 were removed. As shown in Table 2, the variables' CR fulfilled the recommended threshold of $>0.70$, and AVE scores were $>0.50$ (Hair et al. 2017). Discriminant validity was established with Fornell-Larcker criterion where the outer diagonal values were larger than other values (Hair et al. 2017).

Table 2. Internal consistency, convergent validity, and discriminant validity

\begin{tabular}{|l|l|l|l|l|l|l|l|l|}
\hline No & Constructs & AVE & CR & \multicolumn{2}{|l|}{ Fornell-Larcker } \\
\cline { 5 - 10 } & & & & 1 & 2 & 3 & 4 & 5 \\
\hline 1 & LLS & 0.582 & 0.874 & 0.763 & & & & \\
\hline 2 & Reflective thinking & 0.667 & 0.888 & 0.248 & 0.816 & & & \\
\hline 3 & Self-assessment & 0.535 & 0.873 & 0.531 & 0.208 & 0.731 & & \\
\hline 4 & Self-belief & 0.614 & 0.76 & 0.229 & 0.260 & 0.318 & 0.783 & \\
\hline 5 & Teaching awareness & 0.712 & 0.831 & 0.410 & 0.338 & 0.383 & 0.322 & 0.844 \\
\hline
\end{tabular}

LLS $=$ Life-long learning skills

\subsubsection{Structural model evaluation}

In evaluating potential multicollinearity, the variance inflation factor values were assessed. The highest VIF value was lower than the recommended $<3.3$ at 2.251 (Hair et al. 2017). Table 3 shows the results obtained through bootstrapping of 10,000 resamples. Path coefficient significance is determined with t-values $>1.96$, p-values $<0.05$, and also no zero being straddled between the $95 \%$ confidence intervals. As shown below, all hypotheses were supported, except for $\mathrm{H} 2$.

Table 3. Results for hypothesis testing

\begin{tabular}{|c|c|c|c|c|c|c|c|}
\hline \multirow{2}{*}{ Hypotheses } & \multirow{2}{*}{$\beta$} & \multirow{2}{*}{$\begin{array}{l}\text { Stand } \\
\text { Error }\end{array}$} & \multirow{2}{*}{$\begin{array}{c}\text { t-value } \\
(t)\end{array}$} & \multirow{2}{*}{$\begin{array}{l}\mathrm{p}- \\
\text { values }\end{array}$} & \multicolumn{2}{|c|}{$95 \% \mathrm{CI}$} & \multirow[b]{2}{*}{ Support? } \\
\hline & & & & & 0.025 & 0.975 & \\
\hline H1. LLS > RT & $-0.142 * *$ & 0.058 & 2.460 & 0.014 & -0.254 & -0.029 & Yes \\
\hline
\end{tabular}




\begin{tabular}{|l|l|l|l|l|l|l|l|}
\hline H2. Self-assessment $>$ RT & 0.009 & 0.064 & 0.147 & 0.883 & -0.108 & 0.140 & No \\
\hline H3. Self-belief $>$ RT & $0.171^{* *}$ & 0.048 & 3.521 & 0.000 & 0.070 & 0.257 & Yes \\
\hline H4.Teaching Awareness > RT & $0.288^{* *}$ & 0.055 & 5.189 & 0.000 & 0.173 & 0.389 & Yes \\
\hline
\end{tabular}

Note. ${ }^{* *}$ Significant paths. LLS $=$ Life-long learning; RT $=$ Reflective thinking

\subsection{The Qualitative Phase}

The semi-structured interview protocols were employed to encourage consistency at the same time allowing new thoughts and ideas to emerge from the participants (Kvale, 1996). This approach also allowed both the researcher and the participants to make meaning of their experiences with reflective thinking, which Kerrigan (2014) suggest could contribute to support the validity of the results. The interview protocols included questions on each of the constructs in the conceptual framework to enable a better understanding of PSTs perceptions of incorporating and using reflective teaching in their classroom practices. The interviews were transcribed verbatim to facilitate analysis.

\subsubsection{Participants and data collection}

The 11 PSTs that participated in the interviews were students from Bachelor of Education (TESL) programme. Their mean age was 23.5 years. There are no male representatives in the sample as no male PST volunteered to be interviewed.

\subsubsection{Analysis of qualitative data}

Consistent with a parallel design, data sources from quantitative and qualitative procedures were analysed independently. The analysis of the qualitative data began with reading the interview transcripts to capture the general perceptions of PSTs toward reflective thinking. The categories that emerged were: life-long learning skills, self-assessment ability, self-belief, teaching awareness, and reflective thinking, similar to the variables in the conceptual framework. The analysis of the interview data is shown in Table 4

Table 4. Analysis of interview data

\begin{tabular}{|c|c|c|c|}
\hline Categories & Points & Observations & Themes \\
\hline \multicolumn{4}{|l|}{ Reflective thinking } \\
\hline $\begin{array}{l}\text { - Opportunities } \\
\text { for use of } \\
\text { reflective } \\
\text { thinking } \\
\text { - Reflections } \\
\text { about students }\end{array}$ & $\begin{array}{l}\text { PSTs used reflective thinking more } \\
\text { as a formal requirement of their } \\
\text { teaching practicum. Hence, they } \\
\text { appear more rigid in their practice. } \\
\text { They also favour formal writing of } \\
\text { journals and lesson plans. } \\
\text { The PSTs were focused on } \\
\text { students' education and their future } \\
\text { careers. This sentiment appeared } \\
\text { quite authentic as opposed to being } \\
\text { focused on their own performance }\end{array}$ & $\begin{array}{l}\text { The PSTs were familiar } \\
\text { with the idea of reflective } \\
\text { thinking but their } \\
\text { interpretation of it was } \\
\text { varied. }\end{array}$ & $\begin{array}{l}\text { PSTs were strongly focused on assessing } \\
\text { their teaching in terms of students' } \\
\text { outcomes. Therefore, they consistently } \\
\text { saw students' lack of engagement or } \\
\text { understanding as their own responsibility } \\
\text { which needs to be addressed. } \\
\text { Success for their students is expressed in } \\
\text { terms of educational. The PSTs tend to } \\
\text { be more exclusively focused on } \\
\text { educational attainment. }\end{array}$ \\
\hline \multicolumn{4}{|l|}{ Lifelong Learning } \\
\hline $\begin{array}{l}\text { - Intentions to } \\
\text { continue studies } \\
\text { after graduation } \\
\text { - Views about } \\
\text { lifelong learning }\end{array}$ & $\begin{array}{l}\text { The PSTs had intentions to } \\
\text { continue studying with some of } \\
\text { them needing a break before } \\
\text { continuing. They were of the } \\
\text { opinion that lifelong learning is } \\
\text { valuable and natural and it could } \\
\text { occur in many ways. } \\
\text { The PSTs only recognised a very } \\
\text { narrow perspective of lifelong } \\
\text { learning situated in formal settings. }\end{array}$ & $\begin{array}{l}\text { The responses were } \\
\text { similar for all the PSTs. }\end{array}$ & $\begin{array}{l}\text { Generally, the PSTs were more intent } \\
\text { about the immediate challenge of } \\
\text { becoming a good teacher but were open } \\
\text { to the idea of further education in time. }\end{array}$ \\
\hline \multicolumn{4}{|l|}{ Self-assessment } \\
\hline $\begin{array}{l}\text { - Perceptions of } \\
\text { self-assessment }\end{array}$ & $\begin{array}{l}\text { The responses ranged from } \\
\text { positive to negative. When the } \\
\text { PSTs were given negative } \\
\text { feedback there was an emotional } \\
\text { response and used strategies to } \\
\text { review through the lens of } \\
\text { constructive criticism and }\end{array}$ & $\begin{array}{l}\text { There were varied } \\
\text { responses and self- } \\
\text { assessment is expected to } \\
\text { be carried out for their } \\
\text { practicum. They also had } \\
\text { to video themselves but it } \\
\text { is questionable what they }\end{array}$ & $\begin{array}{l}\text { Self-assessment is regarded as important } \\
\text { by all PSTs and have developed a range } \\
\text { of strategies to self-assess. They are } \\
\text { capable of incorporating critical } \\
\text { feedback into the process. It is } \\
\text { recognised that students' core needs and } \\
\text { they are challenged to think of how they }\end{array}$ \\
\hline
\end{tabular}




\begin{tabular}{|c|c|c|c|}
\hline & $\begin{array}{l}\text { recognised that student responses } \\
\text { will impact the way they teach. }\end{array}$ & $\begin{array}{l}\text { actually saw. } \\
\text { Interestingly they did not } \\
\text { question the value of self- } \\
\text { assessments but carried it } \\
\text { out accordingly }\end{array}$ & $\begin{array}{l}\text { meet the needs. They also recognise that } \\
\text { students' reactions will impact how they } \\
\text { teach and the way they respond. The } \\
\text { PSTs assess their success based on their } \\
\text { capacity to meet students' needs. }\end{array}$ \\
\hline \multicolumn{4}{|l|}{ Self-belief } \\
\hline $\begin{array}{l}\text { - } \begin{array}{l}\text { Balancing of } \\
\text { own needs and } \\
\text { students' needs }\end{array}\end{array}$ & $\begin{array}{l}\text { They responded in terms of } \\
\text { prioritising students' needs, only } \\
\text { one talked about their own needs. }\end{array}$ & $\begin{array}{l}\text { They have self-beliefs } \\
\text { that are more contextually } \\
\text { based on their work } \\
\text { situations. }\end{array}$ & $\begin{array}{l}\text { The PSTs had responses that are more } \\
\text { compartmentalised and regulated. They } \\
\text { were more concerned about 'doing it } \\
\text { correctly'. } \\
\text { Teacher education directed by the } \\
\text { National Education Philosophy, is } \\
\text { focused on development of the student in } \\
\text { a holistic manner which encompasses } \\
\text { moral values and personal well-being. }\end{array}$ \\
\hline \multicolumn{4}{|l|}{ Teacher Awareness } \\
\hline $\begin{array}{l}\text { - Perceptions of } \\
\text { effective } \\
\text { teaching } \\
\text { practices }\end{array}$ & $\begin{array}{l}\text { They demonstrated an } \\
\text { understanding there is more than } \\
\text { one model of learning and were } \\
\text { able to share their views about } \\
\text { teaching philosophies. Teaching } \\
\text { strategies used to help student learn } \\
\text { were also identified }\end{array}$ & $\begin{array}{l}\text { Contemporary and } \\
\text { traditional teaching } \\
\text { strategies were used. it } \\
\text { was also recognised that } \\
\text { engagement and } \\
\text { differentiated learning is } \\
\text { valuable in the classroom. }\end{array}$ & $\begin{array}{l}\text { The PSTs demonstrated an } \\
\text { understanding that there is more than one } \\
\text { model of learning. Teaching } \\
\text { philosophies were expressed and beliefs } \\
\text { they held about teaching was sheared and } \\
\text { discussed. They acknowledged the } \\
\text { importance of adopting different } \\
\text { teaching strategies to promote } \\
\text { engagement and facilitate differentiated } \\
\text { learning. }\end{array}$ \\
\hline
\end{tabular}

\section{Discussion of Findings}

The study employed a mixed methods convergent parallel design to identify the contributing factors to the reflective thinking practices of Malaysian PSTs. Data from the two strands are now merged after separate analysis for a more complete understanding of reflective teaching practices. In the quantitative strand four factors: lifelong learning, self-assessment, selfbelief and teaching awareness have in different degrees influenced reflective thinking practices of PSTs. Three hypotheses were significant for the quantitative analysis and analysis of the qualitative data found five categories similar to the factors in the conceptual framework. The interviewees shared similar perceptions of the categories with differences coming from past experiences.

The quantitative data show, lifelong learning skills, the pursuit of knowledge that is self-motivated by personal or professional reasons, significantly influenced reflective thinking. From the qualitative analysis, PSTs were generally focused on the immediate challenge of becoming good teachers and were open to further education in time. The analysis seem to suggest that the PSTs recognises the importance of lifelong learning in helping them to grow in their chosen career. According to Quendler and Lamb (2016) the ability of individuals to self-manage, self-monitor and eventually self-reflect will depend on the lifelong learning undertaken. The openness of the PSTs to lifelong learn may be an indication that they can develop the necessary skills to carry out continuously monitor and improve their teaching skills ultimately develop their ability to teach reflectively.

Quantitative analysis of self-assessment conceptualised as the process of evaluating individual experiences that give rise to reflection, was found not important to reflective thinking. Implying that the PSTs may be perceive assessment as coming from an external source like their mentor teachers rather than from the self. PSTs wanted students' feedback so they are made aware of their strengths and weaknesses. The qualitative data similarly showed that the PSTs perceived self-assessment as important and had developed a range of strategies to self-assess. The focus was on students' needs and the PSTs' capacity to meet those needs. Snead and Freiberg (2017) similarly noted that emphasis on self-assessment generally lies on external explanations and PSTs generally valued students' feedback. It must be further noted that when teachers use self-assessment and self-directed inquiry, they are more likely to sustain the learning (Davis \& McDonald, 2019). Hence, teachers are less inclined to reflect on their own teaching unless it is necessary to re-examine occurrences in the classroom as suggested by Lee (2005).

Self-belief, teachers' perception of own teaching capabilities which can drive improvement in teaching, was quantitatively significant to reflective thinking. The PSTs tended to be more compartmentalised and instrumental in their views about selfbelief. This may be because the Malaysian education system follows a prescriptive curriculum that is centrally controlled by the Ministry of Education in the form of the National Education Philosophy (NEP) which emphasises the holistic training to achieve national unity and increase economic standards of the country. Using national culture as a lens, there is evidence of such influence from the questionnaire item that scored the largest loading for self-belief. This item concerns how the mistakes made by teacher can influence a students' life, and indicates that PSTs tend to follow supervisors' instructions to make sure 
they teach 'correctly'. It also suggests that PSTs with high self-belief will have the confidence to practice reflective thinking independently.

Teaching awareness, teachers' realisation of their capability to influence students which in turn encourages self-assessment and self-evaluation, significantly affected reflective thinking. The highest factor loading in this scale was the item on the effect of the control of belief on teaching behaviour and students. Similarly, results of the qualitative thread showed the PSTs were able to manage their planning, monitoring of students and evaluation of themselves in relation to their students which indicate metacognitive awareness, a good indicator of well-established reflective thinking processes as suggested by Adadan and Oner (2018). However, the depth of the thinking processes cannot be established. Previous research has shown that many PSTs were only capable to think reflectively at a rudimentary rather than critical level (Subramanian, 2012). The results again seem to suggest that the PSTs were more conscious about the influence of their actions on students.

\subsection{Implications for Practice}

The study found some evidence that suggest PSTs may be carrying out some extent of independent self-reflection albeit from different contexts. The reflections of these PSTs seem more procedural and instruction oriented rather than on a social constructivists basis where knowledge is constructed through interactions with others. Based on the analysis of the quantitative data, the PSTs had thought reflectively but perceived it more useful to reflect on teaching practices according to feedback from students and especially from supervisors. The qualitative analysis showed that these PSTs strongly reflected on the reactions they received from students and focus mainly on education attainment. There was no mention from these PSTs about developing a love for learning. However, it must be noted that the reflections of some of the PSTs were mainly on a surface and technical level. PSTs expressed more compartmentalised and regulated views of teaching. They were more concerned about getting it done correctly rather than focussing on the learning that takes place.

\section{Study Limitations}

Data were collected from only one Malaysian education university. Further to this the responses may vary if the context and situation of the respondents change as self-reported instruments were used. It is also expected that the respondents' context and interpretation of the questions may influence their answers to the interview questions.

\section{Conclusion}

This study showed some interesting new findings. The qualitative thread showed that the PSTs carried out some form of reflective thinking in their work. When the qualitative results were analysed together with the quantitative results it revealed greater insights into the reflective thinking being carried out. In this study, the weaknesses of one method was complemented by the strengths of the other method. The quantitative analysis showed evidence that lifelong learning skills, self-belief, and teaching awareness were important for reflective thinking of PSTs. These PSTs consider lifelong learning important and may consider furthering their education. For self-belief and teaching awareness, the reflection of the PSTs were more work oriented and less social in nature. Their reflection were also more on the surface level and lacked critical thinking. Future studies will need to consider how this will influence how reflective thinking is carried out when they are practicing teachers.

\section{References}

Adadan, E., \& Oner, D. (2018). Examining preservice teachers' reflective thinking skills in the context of web-based portfolios: The role of metacognitive awareness. Australian Journal of Teacher Education , 43(11), 26-50.

Buehl, M. M., \& Fives, H. (2009). Exploring teachers' beliefs about teaching knowledge: Where does it come from? Does it change? The Journal of Experimental Education, 77(4), 367-407. https://doi.org/10.3200/JEXE.77.4.367-408.

Choy, S. C., Yim, J. S., \& Tan, P. L. (2017). Reflective thinking among preservice teachers:A Malaysian perspective. Issues in Educational Research, 27(2), 234-251.

Clara, M. (2014). What is reflection? Looking for clarity in an ambigious notion. Journal of Teacher Education, 66(3) 261271. DOI: $10.1177 / 0022487114552028$.

Cox, E. (2005). Adult learners learning from experience: Using a reflective practice model to support work-based learning. Reflective Practice, 6(4),459-472. https://doi.org/10.1080/14623940500300517.

Creswell, J. W., \& Plano Clark, V. L. (2011). Designing and conducting mixed methods research. Los Angeles: Sage.

Crosswell, L., \& Beutel, D. (2017). 21st century teachers: how non-traditional pre-service teachers navigate their initial experiences of contemporary classrooms. Asia-pacific Journal of Teacher Education, 1-16. http://dx.doi.org/10.1080/1359866X.2017.1312281.

Farrell, S. C. (2015). The practices of encouraging TESOL teachers to engage in reflective practices: An appraisal of recent research contributions. Language Teaching Research, 20(2) 223-247, DOI: 10.1177/1362168815617335.

Goh, P. S., \& Wong, K. T. (2014). Beginning teachers' conceptions of competency: implications to educational policy and teacher education in Malaysia. Education Research Policy, 13:65-79. DOI 10.1007/s10671-013-9147-3.

Hair, J. F., Hult, G. T., Ringle, C. M., \& Sarstedt, M. (2017). A primer on partial least squares structural equation modelling (PLS-SEM). Los Angeles: Sage.

Hanushek, E., \& Woessmann, L. (2015). Universal basic skills: What countries stands to gain. London: OECD. 
Kabilan, M. K. (2007). English language teachers reflecting on reflections: A malaysian expereince. TESOL Quarterly, 41(4): 681-705.

Kek, M., \& Huijser, H. (2011). Exploring the combined relationships of student and teacher factors on learning approaches and self-directed learning readiness at a Malaysian university. Studies in Higher Education, Megan Kek \& Henk Huijser (2011) Exploring the combined relationships of student and teacher factors on learning approaches and selfdirected learning readiness at a Malay 36(2), 185-208. DOI: 10.1080/03075070903.

Kerrigan, M. R. (2014). A framework for understanding community college' organisational capapcity for data use: A convergent parallel mixed method study. Journal of Mixed Methods Research, 8(4) 341-362. DOI: $10.1177 / 1558689814523518$.

Lee, H.-J. (2005). Understanding and assessing preservice teachers' reflective thinking. Teaching and Teacher Education, 21(6), 699-715. https://doi.org/10.1016/j.tate.2005.05.007.

Ministry of Education Malaysia. (2015). Malaysia Education Blueprint 2015-2025 (Higher Education). Putrajaya: Ministry of Education Malaysia.

Mustapha, S. I. (2013). Amalan bimbingan pengajaran pensyarah dan guru pembimbing dalam program mentoring praktikum serta impaknya terhadap kualiti guru pelatih. Jurnal Pendidikan Malaysia, 38(1), 71-78.

Nambiar, R. M., \& Thang, S. (2015). Examining Malaysian teachers' online blogs for reflective practices: towards teacher professional development. Language and Education, 1-15. http://dx.doi.org/10.1080/09500782.2015.1071386.

Nasir, S. M., \& Sulaima, N. F. (2015). Pemikiran Reflektif: Meneroka Amalan Pemikiran Siswa Pendidik. (Reflective Thinking: Exploring Thinking Practices in Student Teachers). Jurnal Personalia Pelajar, 18(2), 61-68.

Nordin, A. B., Alias, N., \& Siraj, S. (2013). Assessing quality assurance for teaching and learning in higher education in Malaysia: Reflecting on its policy and processes. Life Science Journal, 10(1), 1222-1232.

Ong, W. A., Swanto, S., \& Al-Saqqaf, A. (2018). Pre-service ESL teachers engaging in reflective practice: Current observations and perceived challenges. Policy \& Practice of Teachers \& Teacher Education, 8(2), 5-18.

Quendler, E., \& Lamb, M. (2016). Learning as a lifelong process - meeting the challenges of the changing employability landscape: competences, skills and knowledge for sustainable development. International Journal of Continuing Engineering Education and Life-Long Learning, 26(3), 273-293. doi:10.1504/ijceell.2016.078447.

Rodgers, C. (2002). Defining refelction: Another look at John Dewey and reflective thinking. Teachers College Record, 104(4), 842-866.

Senom, F., Zakaria, A. R., \& Ahmad Shah, S. S. (2013). Novice Teachers' Challenges and Survival: Where do Malaysian ESL Teachers Stand? American Journal of Educational Research, 1(4), 119-125. DOI:10.12691/education-1-4-2.

Tan, S. Y., \& Halili, S. H. (2015). Effective teaching of higher-order thinking (HOT) in education. The Online Journal of Distance Education and e-Learning, 3(2), 41-47.

Williams, M., \& Burden, R. L. (1997). Psychology for Language Learners. London: Cambridge University Press. 